\title{
PROGRAM KEMITRAAN MASYARAKAT USAHA KREATIF SARI KEDELAI ARSYA DESA NGIJO KECAMATAN KARANGPLOSO KABUPATEN MALANG
}

\author{
Hendy Hermawan ${ }^{1)}$, Nur Laily Hawa $E^{2)}$ \\ ${ }^{1,2)}$ STIE Indocakti Malang \\ e-mail: hendy.indocakti@gmail.com ${ }^{1)}$,nurlaily.hawa@gmail.com²),
}

\begin{abstract}
Abstrak
Sari Kedelai Arsya merupakan bagian dari usaha kreatif rumahan yang didirikan oleh ibu Yesa sejak tahun 2014. Berbagai kendala hingga saat ini dialami ibu Yesa untuk mengembangkan usahanya, seperti terbatasnya kapasitas mesin dalam proses produksi, terbatasnya tempat penyimpanan hasil pengolahan setengah jadi kedelai yang sudah di rebus, sehingga membuat ibu Yesa membatasi proses produksinya, proses penyaringan dengan menggunakan alat yang sangat sederhana sehingga berakibat lambatnya proses produksi, juga terbatasnya kesediaan produk hanya dalam kemasan botol membuat usaha sari kedelai Arsya tidak maksimal dalam memenuhi kebutuhan pasar yang ada. Sedangkan masalah manajerial dalam bisnis ini belum dikelola dengan baik, keuangan tidak tercatat dengan baik, pemasaran khususnya promosi belum dilaksanakan dengan cara maksimal padahal peluang pasar masih terbuka lebar, sehingga permintaan masih belum bisa terpenuhi. Masalah manajerial ini masih belum menjadi perhatian utama tetapi menjadi masalah yang secara implisit akan mempengaruhi perhitungan keuntungan usaha.

Tujuan program PKM ini adalah berupaya mengatasi beberapa masalah yang dihadapi sari kedelai Arsya, yaitu dengan cara: 1) mendesain dan merancang mesin produksi berupa mesin penghasil sari kedelai yang dapat langsung memenuhi standar mutu bahan baku sari kedelai, 2) mendesain dan merancang mesin untuk memisahkan sari kedelai dengan ampasnya, 3) mendesain dan merancang mesin untuk menyimpan kedelai, 4) mendesain dan merancang mesin sealer dalam bentuk gelas cup sebagai upaya diferensiasi kemasan, 5) memberikan pelatihan dan pendampingan dalam bidang manajemen usaha, pemahaman tentang jobdiskripsi, pembukuan sederhana, perhitungan harga pokok penjualah dan perhitungan BEP, penanganan pemasaran dan promosi.
\end{abstract}

Kata Kunci : Usaha kreatif, inovasi, UKM, kinerja manajerial

\section{PENDAHULUAN}

Sari kedelai merupakan minuman yang memiliki nilai gizi tinggi, terutama karena kandungan proteinnya. Selain itu sari kedelai juga mengandung lemak, karbohidrat, kalsium, fosfor, zat besi, provitamin A, vitamin B kompleks dan air (Koswara 2006b). Sari kedelai memiliki berbagai manfaat diantaranya, sebagai antioksidan, mengurangi risiko penyakit jantung, mencegah kanker, mencegah osteoporosis, mengatasi masalah menopause, dan dapat menjaga berat badan. Banyaknya manfaat yang terdapat pada sari kedelai, ditambah dengan mudahnya mendapatkan bahan baku, harganya yang terjangkau, peluang pasar yang masih luas serta proses pembuatan sari kedelai yang sangat sederhana, membuat sari kedelai banyak dilirik pengusaha untuk dijadikan lahan bisnis.

Sari Kedelai Arsya merupakan bagian dari usaha kreatif rumahan yang didirikan oleh ibu Yesa sejak tahun 2014. Awal didirikan, ibu Yesa memproduksi sari kedelai hanya dari $1 \mathrm{~kg}$ kedelai yang dikerjakan sendiri didapur rumahnya. Hingga kini, ibu Yesa mampu memproduksi sari kedelai dari bahan baku kedelai $8 \mathrm{~kg}$ tiap harinya. Tentunya berbagai kendala hingga saat ini dialami ibu Yesa untuk mengembangkan usahanya, misalnya terbatasnya kapasitas mesin sari kedelai dalam proses produksi, tidak adanya tempat penyimpanan khusus hasil pengolahan kedelai setengah jadi yang sudah direbus, sehingga membuat ibu Yesa membatasi proses produksinya, proses penyaringan sari kedelai dengan menggunakan alat yang sangat sederhana sehingga berakibat lambatnya proses produksi, juga terbatasnya kesediaan produk hanya dalam kemasan botol membuat usaha sari kedelai Arsya tidak maksimal dalam memenuhi kebutuhan pasar yang ada sehingga masalah-masalah tersebut membuat usaha sari kedelai Arsya menjadi terhambat untuk berkembang.

manajerial dalam bisnis ini belum dikelola dengan baik, keuangan tidak tercatat dengan baik, pemasaran khususnya promosi belum dilaksanakan dengan cara maksimal. Usulan kegiatan PKM yang 
akan dilakukan oleh Tim Pelaksana diarahkan untuk memberikan solusi atas beberapa permasalahan yang dihadapi mitra yaitu Sari Kedelai Arsya agar dapat memberikan semangat dan tambah berkembang menjadi usaha kreatif yang menjanjikan serta contoh untuk usaha sejenis yang digeluti oleh masyarakat.

\section{METODE KEGIATAN}

Permasalahan yang dihadapi oleh mitra, yaitu permasalahan dalam ketersediaan mesin pendukung dalam proses produksi serta managerial dalam promosi dan administrasi keuangan, maka kegiatan PKM ini menitikberatkan pada beberapa solusi, yakni: 1) mendesain dan merancang mesin produksi berupa mesin penghasil sari kedelai, 2) mendesain dan merancang mesin untuk memisahkan sari kedelai dengan ampasnya, 3) mendesain dan merancang mesin untuk menyimpan kedelai, 4) mendesain dan merancang mesin sealer dalam bentuk gelas cup sebagai upaya diferensiasi kemasan, 5) memberikan pelatihan dan pendampingan dalam bidang manajemen usaha, pemahaman tentang jobdiskripsi, pembukuan sederhana, perhitungan harga pokok penjualah dan perhitungan $\mathrm{BEP}$, penanganan pemasaran dan promosi.

Kegiatan pengabdian ini dilakukan dengan beberapa tahapan, yaitu: 1) Mendesain mesin yang dibutuhkan oleh sari kedelai Arsya. Dalam hal ini, tim bekerjasama dengan mahasiswa Politeknik Negeri Malang yaitu Yulfarida dari jurusan Teknik Mesin, 2) Merancang mesin. Dalam hal ini tim meyerahkan hasil desain ke bengkel mesin, yaitu Bapak Ibnu, 3) Memberikan pelatihan dan pendampingan dalam hal manajerial.

\section{1) Mendesain Mesin}

Proses desain mesin dilakukan oleh tim pengabdian, yaitu tim bekerjasama dengan mahasiswa Politeknik Negeri Malang yaitu Yulfarida dari jurusan Teknik Mesin. Mesin didesain sesuai dengan yang dibutuhkan oleh sari Kedelai Arsya.

Berikut beberapa hasil desain mesin yang ditawarkan pada mitra:

a) Mesin Olah Sari kedelai

Mesin yang dirancang menggunakan spesifikasi: voltase: 220-240 volt; Material: stainless steel; kapasitas: 40liter.

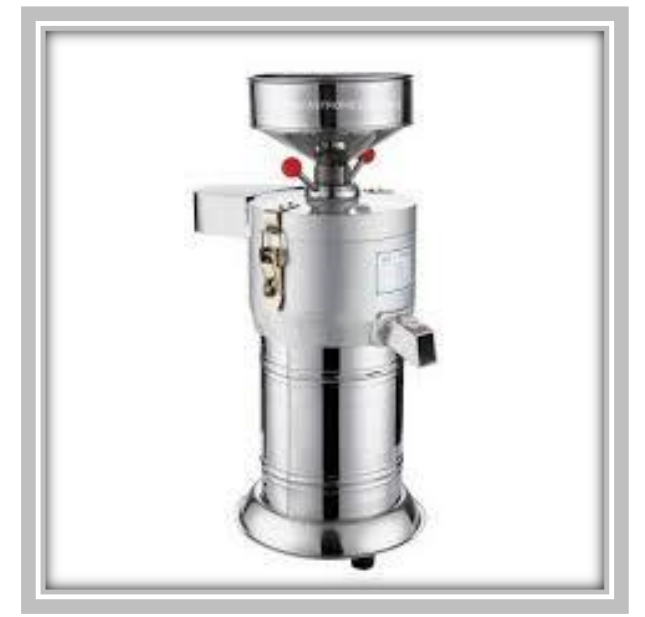

Gambar 1. Mesin Sari Kedelai

b) Mesin Penyimpanan

Mesin ini dirancang dengan spesifikasi: memiliki volume 480liter; Dimensi: 595x680x1840 mm; Temperature: 3-22C; Shelf: 4.

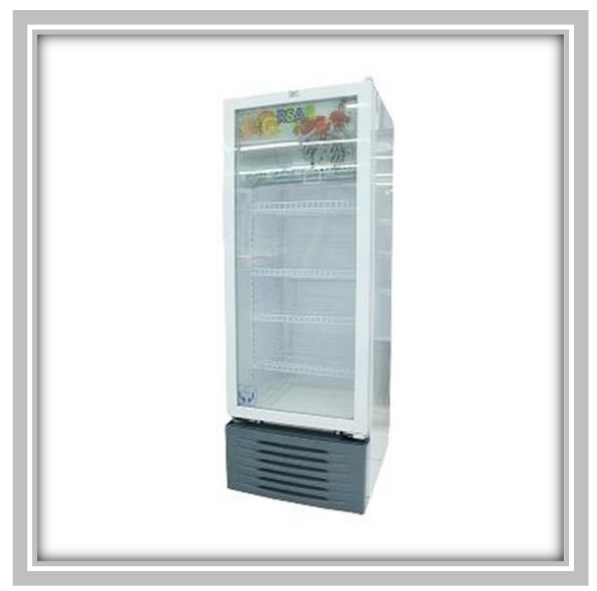

Gambar 2. Mesin Penyimpanan

c) Mesin Peras

Mesin ini memiliki spesifikasi: Dimensi: 50x40x120cm; Bahan ulir: As besi 1 1/2.

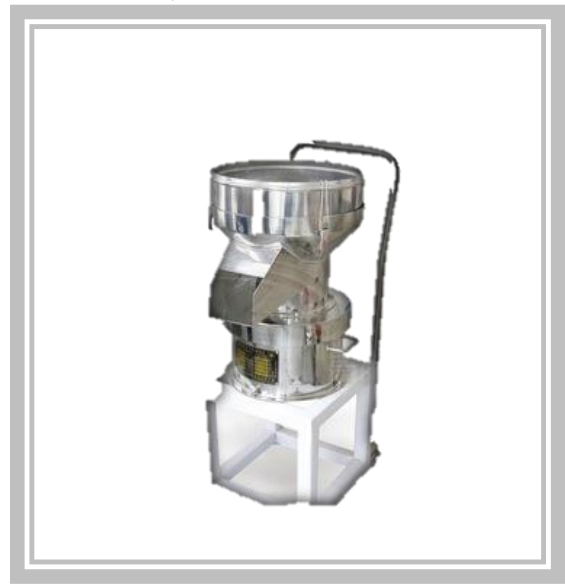

Gambar 3. Mesin Peras Sari kedelai 
d) Mesin Cup Sealer

Cup Sealer ini adalah alat mesin untuk menyegel gelas plastik minuman. Body dari bahan stainless steel dan aluminium. Higienis, mudah digunakan dan praktis.terdapat 2 buah dudukan untuk ukuran gelas kecil dan besar.Voltage: 220 VFrequency: 50/60 HzPower: 300W. Capacity: 300-400 cup/hr. Machine Size: 29 x 24 x $48 \mathrm{~cm}$. Ukuran leher gelas khusus gelas local.

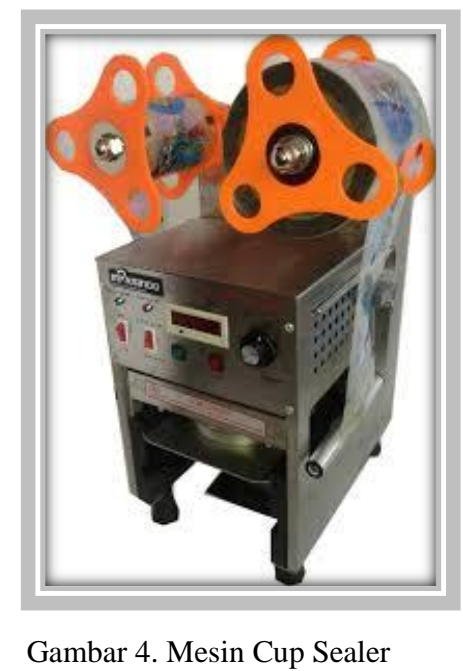

2) Merancang / Membuat Mesin

Dari hasil desain yang sudah dibuat/dirancang, tim menyerahkan hasil desain tersebut untuk dibuatkan mesin di bengkel. Berikut hasil rancangan mesin sari kedelai dari proses perendaman kedelai sampai sarikedelai siap dimasukkan dalam kemasan:

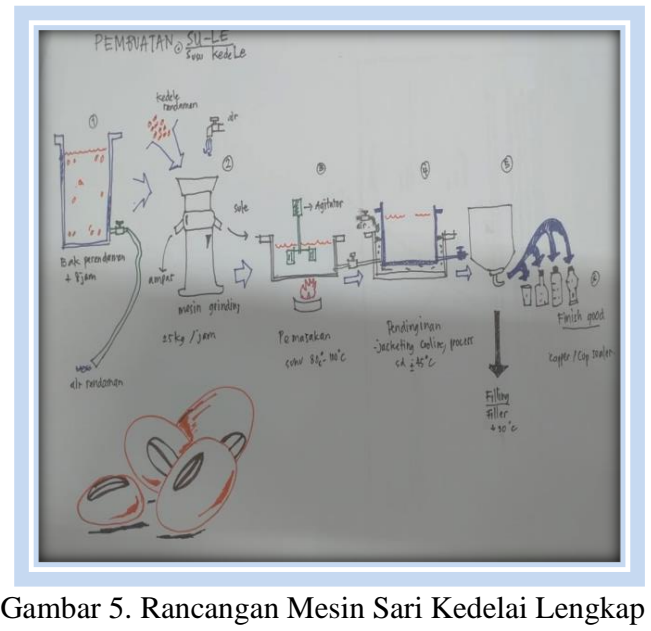

\section{3) Memberikan Pelatihan dan Pendampingan}

Kegiatan pelatihan dan pendampingan dilaksanakan sebagai modal bagi Sari
Kedelai Arysa dalam mengelola usahanya agar lebih baik lagi.

a) Pelatihan dan Pendampingan Kegiatan Pembukuan, Perhitungan harga pokok penjualan (HPP) dan perhitungan BEP

Pelatihan dilakukan pada hari jumat tanggal 02, jam 14.00 pelatihan ini diisi oleh Bapak Hendy Hermawan, SE.,MM sebagai pemateri.

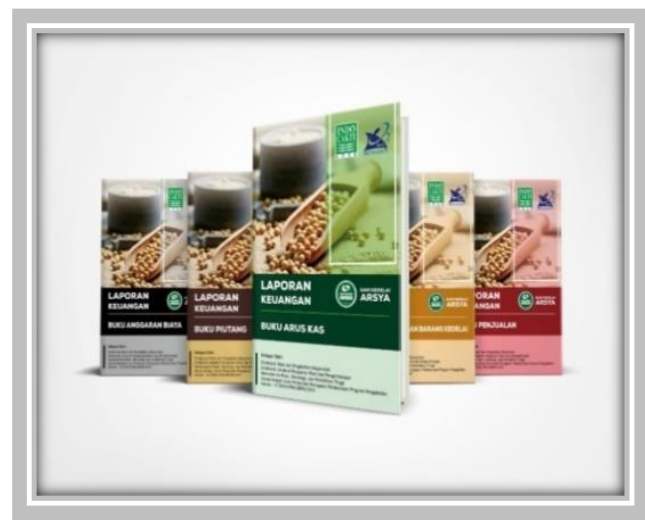

Gambar 6. Desain Buku yang akan digunakan dalam pelatihan dan pedampingan

b) Pelatihan dan Pendampingan Kegiatan Promosi

Pelatihan dilakukan pada hari Selasa tanggal 06 Agustus 2019, jam 14.00 pelatihan ini diisi oleh Ibu Nur Laily Hawa E, SE.,MM sebagai pemateri.

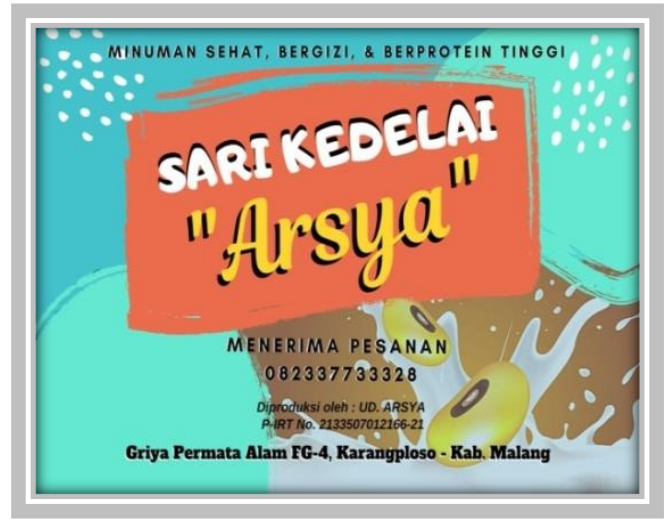

Gambar 7. Desain Banner sebagai bagian dari media promosi

\section{HASIL DAN PEMBAHASAN}

\section{1) Kegiatan Operasional Sari Kedelai Arsya}

Selama ini proses produksi pembuatan sari kedelai Arsya melalui beberapa tahapan, yaitu: dimulai dari membeli kedelai di Koperasi $\rightarrow$ kedelai di rendam (minimal 6 jam dan maksimal 8 jam) $\rightarrow$ Kedelai yang sudah direndam direbus 
(sampai mendidih) $\rightarrow$ Tiriskan dan bersihkan kedelai dari kulit ari $\rightarrow$ Giling kedelai yang sudah bersih (diblender hingga halus) $\rightarrow$ Rebus bubur kedelai (sampai mendidih) $\rightarrow$ Saring bubur kedelai (ampas kedelai dibuang) $\rightarrow$ Beri perasa pada sari kedelai $\rightarrow$ Sari kedelai siap dimasukkan dalam kemasan botol
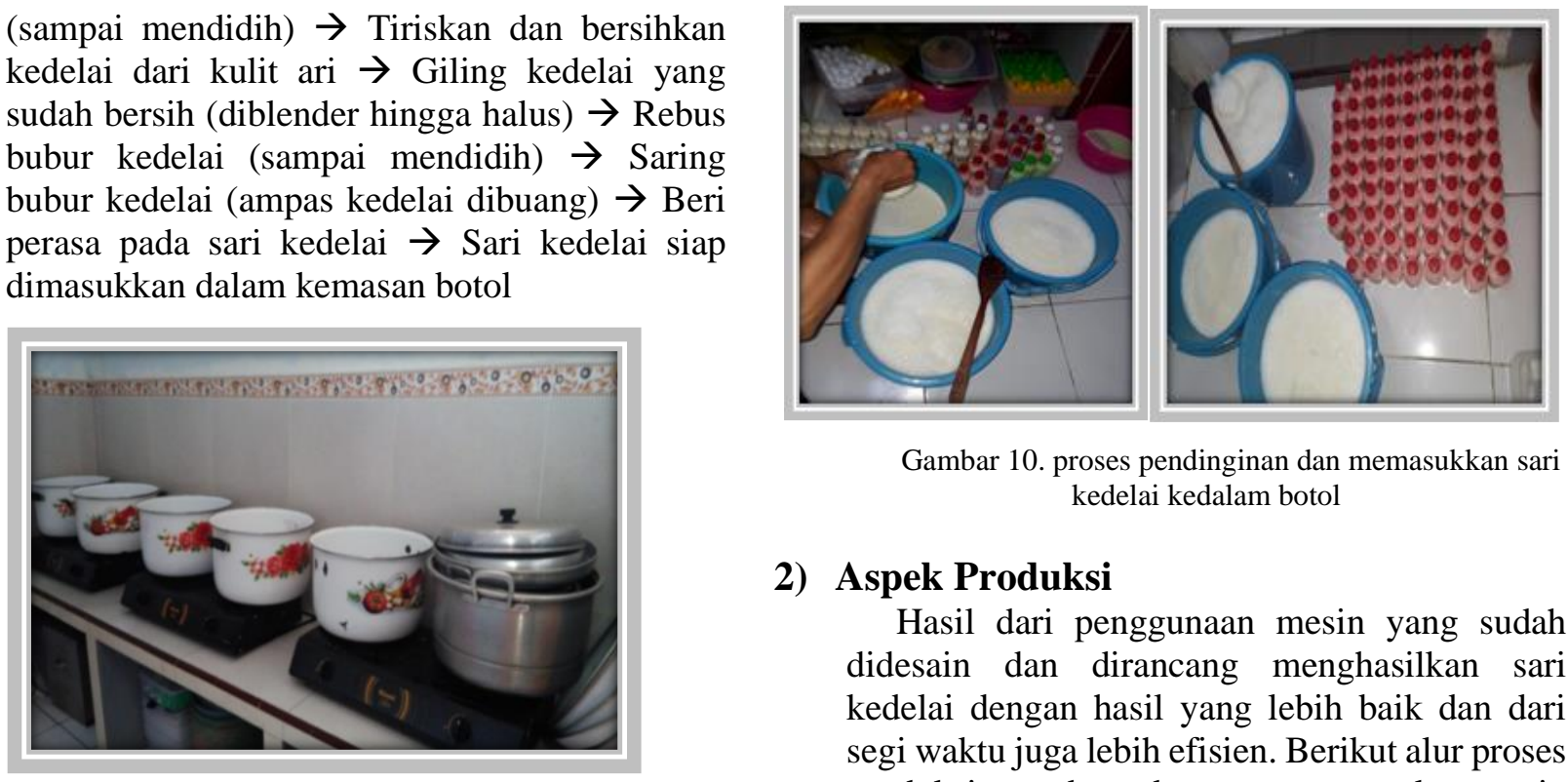

Gambar 10. proses pendinginan dan memasukkan sari kedelai kedalam botol

\section{2) Aspek Produksi}

Hasil dari penggunaan mesin yang sudah didesain dan dirancang menghasilkan sari kedelai dengan hasil yang lebih baik dan dari segi waktu juga lebih efisien. Berikut alur proses produksi yang baru dengan menggunakan mesin yang sudah dirancang:

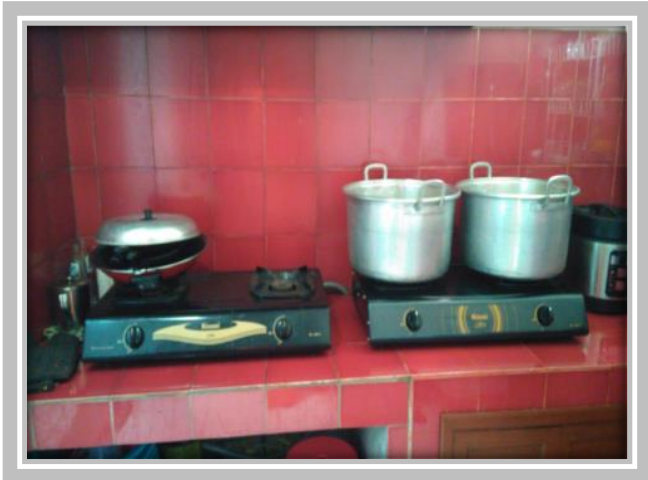

Membeli kedelai di Koperasi $\rightarrow$ kedelai langsung dimasukkan ke dalam mesin (didalam mesin, mesin merendam kedelai, dan langsung menggiling dan memasak kedelai) $\rightarrow$ kedelai matang siap diberi perasa $\rightarrow$ Sari kedelai siap dikemas.

\section{3) Aspek Manajemen}

Hasil dari pelatihan dan pendampingan manajerial pada Kegiatan Promosi dan kegiatan Pembukuan, Perhitungan harga pokok penjualan (HPP) dan perhitungan BEP adalah, Mitra sudah memahami dasar dalam perhitungan HPP, BEP, dan dapat melakukan kegiatan pembukuan sederhana.

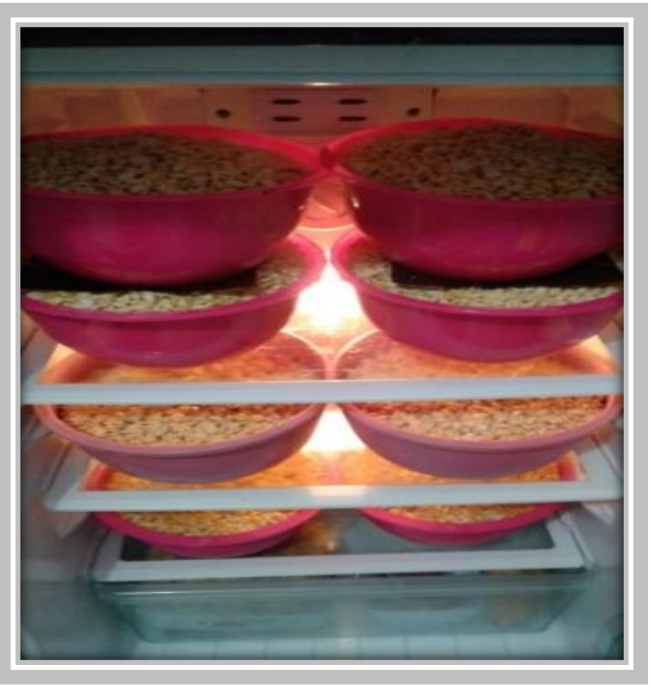

\section{4) Potensi dan Peluang Sari Kedelai Arsya}

Keberlanjutan program setelah selesai kegiatan PKM dilaksanakan adalah berencana melanjutkan program tersebut ke skim PPK (Program Pengembangan Kewirausahaan). Program akan mencari potensi/keunggulan dari sari kedelai atau turunannya, sehingga usaha ini bisa lebih berkembang lagi.

\section{5) Pelaksanaan Kegiatan}

Hasil yang sudah dicapai dalam pelaksanaan pengabdian Program Kemitraan Masyarakat (PKM) ini adalah:

Gambar 9. proses penyimpanan kedelai setengah matang 
1. Pengadaan Mesin sari kedelai dan mesin Peras

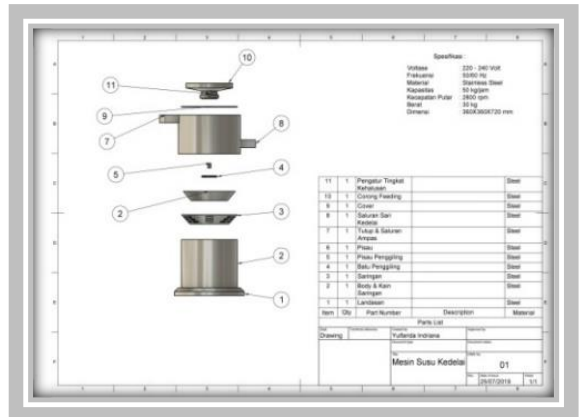

Gambar 11. Mesin sari kedelai dan mesin Peras

2. Pengadaan Mesin penyimpanan

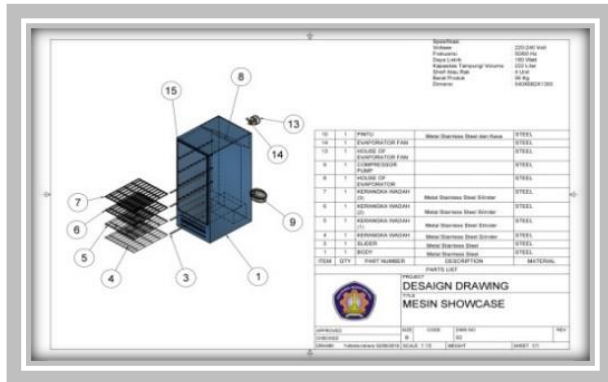

Gambar 12. Mesin Penyimpanan

3. Pengadaan Mesin Cup Sealer

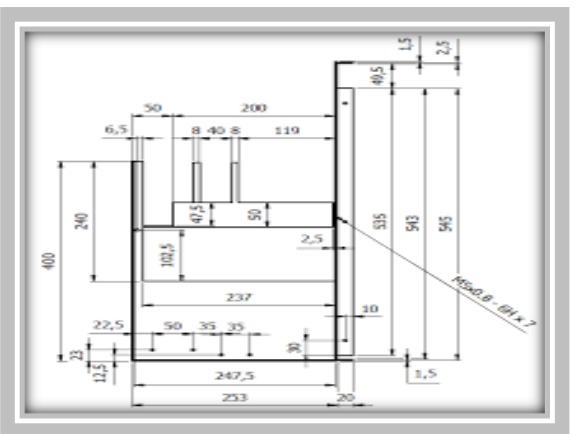

Gambar 13. Mesin Cup Sealer

4. Pelatihan Kegiatan Pembukuan, Perhitungan Harga Pokok Penjualan (HPP) dan Perhitungan BEP
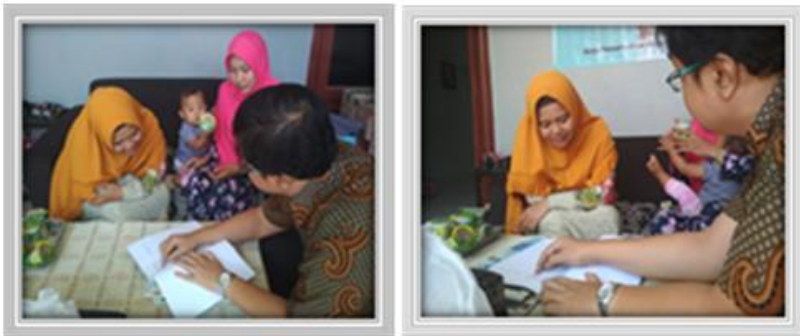
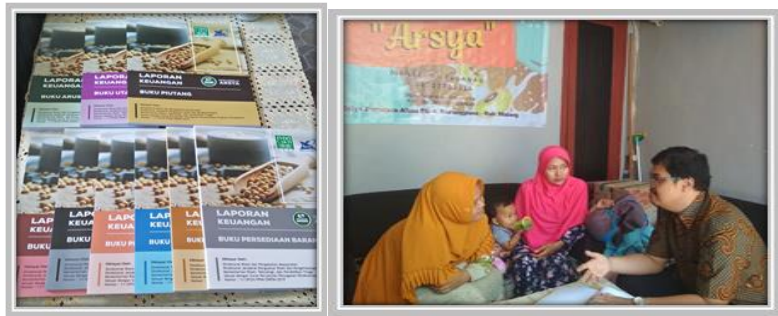

Gambar 14. Pelatihan manajemen keuangan

5. Pelatihan Manajemen Promosi

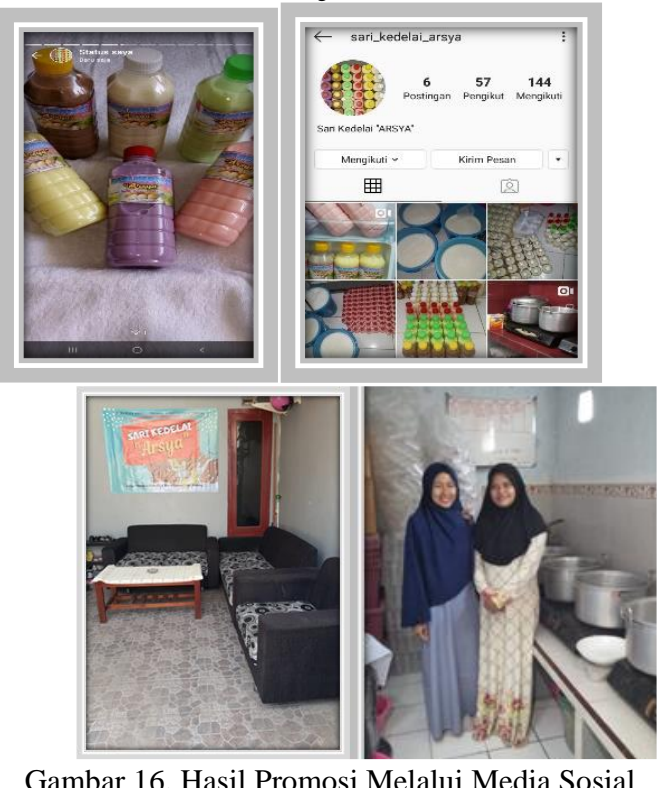

IV. KESIMPULAN DAN SARAN

\section{Kesimpulan}

Kesimpulan dari program PKM yang telah dilaksanakan pada sari kedelai Arsya yang berlokasi di desa ngijo kabupaten Malang ini adalah sebagai berikut:

1. Pengadaan mesin penunjang dalam proses produksi meliputi: mesin pembuat sari kedelai, showcase, mesin peras, dan mesin cup sealer.

2. Pelatihan dan pendampingan dalam manajemen usaha, Pemaparan pentingnya jobdiskripsi, Pelatihan pembukuan sederhana, Pelatihan perhitungan harga pokok penjualan dan perhitungan BEP, serta Pelatihan manajemen pemasaran (promosi).

\section{Saran}

Dengan adanya program pemberdayaan masyarakat melalui peningkatan produksi dan manajemen pada usaha sari kedelai Arsya ini diharapkan mampu meningkatkan nilai tambah dan keberlanjutan usahanya sehingga dapat meningkatkan roda perekonomian masyarakat. 


\section{REFERENSI}

Koswara, 2006, Teknologi Modifikasi Pati. Ebook Pangan

https://lifestyle.kompas.com/read/2011/07/13/15145

479/8.Manfaat.Kedelai.Bagi.Kesehatan?page=a 11 https://finance.detik.com/berita-ekonomi-bisnis/d4119386/jadi-penggerak-ekonomi-beginikondisi-umkm-ri

https://www.alodokter.com/manfaat-susu-kedelaibagi-kesehatan

https://www.jurnal.id/id/blog/2017-perbedaanumkm-perkembangannya-di-indonesia/ 